\title{
Tobacco control policies in Ukraine: history, public health impact, and current priorities
}

Liliia Olefir

NGO Advocacy Center "LIFE", Kyiv, Ukraine

\begin{abstract}
Ukraine is one of the largest countries in Eastern Europe, with a higher smoking prevalence among men and considerably lower smoking prevalence among women in comparison to Western Europe. Since 2005 Ukraine has adopted national tobacco control policies based on the WHO FCTC recommendations. In the last years anti-tobacco advocacy campaigns are mostly driven by non-governmental organizations in Ukraine. However, despite the reduction of tobacco products' affordability, driven by a significant increase of tobacco taxes and an economic recession, the price of cigarettes in Ukraine is still one of the lowest in the world. In addition, the lack of political will and tobacco industry interference have led to an absence of new non-price tobacco control laws in the last five years. Robust political leadership, and greater collaboration of the authorities with civil society are needed for Ukraine to progress towards comprehensive WHO FCTC implementation; the development of a national plan to prevent smoking initiation among children and teenagers, wider promotion of national smoking cessation service, and the implementation of a code of conduct for avoiding tobacco industry interference while setting public health tobacco control policies.
\end{abstract}

KEY WORDS: tobacco control, health advocacy, Ukraine, public health, smoking, taxation, smoke-free, tobacco advertising.

ADDRESS FOR CORRESPONDENCE: Liliia Olefir, NGO Advocacy Center "LIFE”, 32 B. Khmelnytskoho Street, office 29, 01030 Kyiv, Ukraine, phone: +380938565665, e-mail: lea.olefir@gmail.com

\section{INTRODUCTION}

At the end of the 1990s, smoking prevalence in Ukraine was on the rise. The annual consumption of cigarettes stood at about $60-70$ billion sticks. After the year 2000 the consumption grew further, and by 2005 2006 legal sales of cigarettes rose to about 116 billion [1]. At that time inflation-adjusted household income in Ukraine had been growing, while the prices of cigarettes (with adjustment for inflation) fell by 30\% between 1999 and 2006. In 2007, 128 billion cigarettes were produced in Ukraine $[2,3]$.

The implementation of the WHO FCTC policies in the country, and the adoption of the first Tobacco Control Law in 2005, have helped to reverse this negative trend and contributed to a significant reduction of smoking prevalence $[1,4]$. Ukrainian government, parliament, and civil society have made enormous progress in saving lives in Ukraine by raising tobacco taxes and cigarette prices, discouraging the initiation of smoking by kids and youth, reducing tobacco availability and affordability, as well as the attractiveness of smoking, and encouraging smokers to quit or reduce the number of cigarettes consumed, while also raising awareness of the danger caused by tobacco. Smoke-free policies have reduced the exposure of Ukrainians to second-hand smoke, while the tobacco advertising, promotion, and sponsorship ban contributed to denormalization of tobacco use in Ukraine [4]. The WHO FCTC policies that were implemented in Ukraine facilitated the substantial reduction of tobacco consumption, from a $67 \%$ smoking prevalence (including occasional smokers) among Ukrainian men in 2005, to $39.7 \%$ today. Nonetheless, Ukraine remains a country with high male smoking rates in comparison to Western European states, with a total of 6.5 million male smokers $[1,4]$.

In addition, it is concerning that no new non-price tobacco control policies have been adopted in Ukraine 
since 2012, meaning that for the last five years there has not been any further progress in WHO FCTC implementation. During this period the tobacco industry successfully delayed the adoption of new anti-tobacco legislation by misleading and manipulating decision makers and public opinion, and discrediting civil society organizations advocating for policy change. Four transnational tobacco companies have interfered with tobacco control policymaking, and attempted to prevent policymakers from pursuing an anti-tobacco legislative agenda $[5,6]$.

\section{IMPLEMENTATION OF TOBACCO CONTROL POLICIES}

Before a comprehensive Tobacco Control Law was adopted in Ukraine, cigarettes were regulated by several legislative amendments introduced in 1984, 1995 and 1996 prohibiting smoking in public and workplaces, introducing packaging and labeling laws, restricting the sale of tobacco products, and regulating their advertising and sponsorship [7]. Ukraine ratified the WHO Framework Convention on Tobacco Control in 2006. The ratification took place one year before the first Tobacco Control Law was adopted. This law regulated packaging and labeling of tobacco products, restricted smoking in public places, regulated the content of tobacco products, and introduced penalties for violations of provisions of this law [8]. After Ukraine became a Party to the WHO FCTC, the primary Tobacco Control Law was amended four times in 2009, 2010, 2011 and 2012 [8].

As of May 2018 smoking of tobacco products, electronic cigarettes and water pipe is prohibited in public places, including government facilities, cafes, bars, restaurants, nightclubs, healthcare facilities, educational institutions, children's playgrounds, sports facilities, entrances to residential buildings, underground passages, elevators, public transport, and public pay phones [8]. In workplaces and other public places, smoking is permitted only in designated areas. All forms of tobacco sponsorship, promotion, and advertisement are prohib-

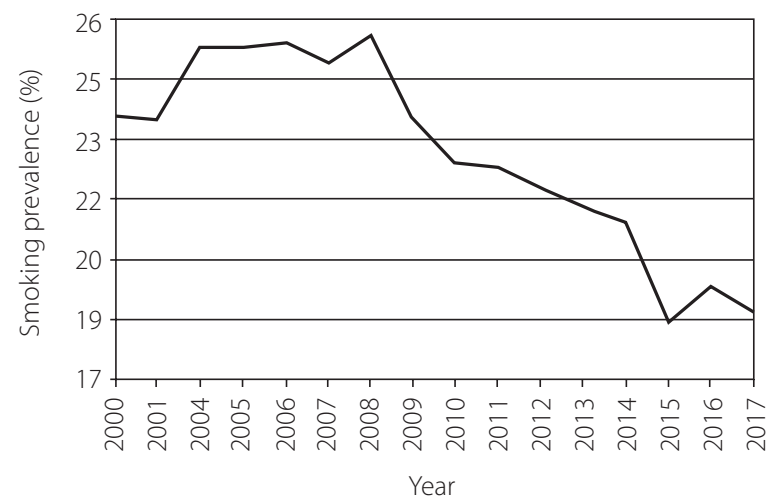

FIG. 1. Smoking prevalence in the population age over 12 years, Ukraine, 2000-2017. According to State Statistics Committee. Population's Self-perceived of Health Status and Availablity of Selected Types of Medical Aid ited, except tobacco advertisement on Internet websites to people over 18, and tobacco product displays at points of sale. Pictorial health warnings must cover $50 \%$ of one side of cigarette packs and text warnings should be printed on the other side. The use of misleading information on tobacco packaging is prohibited [8].

In addition, price mechanisms were used to decrease smoking prevalence in Ukraine. Between 2008 and 2017 tobacco taxes were increased 20-fold. Between 2010 and 2017, the median price for a pack of twenty cigarettes grew by almost $70 \%$, while the affordability of cigarettes (share of cigarette price in GDP per capita) decreased by $30 \%$. These measures drove the overall drop in cigarette consumption in the same period by $28 \%$ [2]. In 2017, the government of Ukraine adopted a seven-year plan to increase specific tobacco excise taxation by $30 \%$ in 2018 and by $20 \%$ annually between 2019 and 2024 . Since well-implemented tobacco tax increases are one of the most effective tobacco control measures, this decision could yield substantial public health benefit. A further hike of tobacco excise taxes could be achieved through annually adjusting the proposed tax increase for inflation rate and considering additional strategies to decrease affordability of tobacco products, in particular by simplifying the tobacco tax structure.

\section{IMPACT ON SMOKING PREVALENCE}

The results of the Global Adult Tobacco Survey conducted in 2017 show that daily smoking prevalence among Ukrainians aged over 15 has dropped from 25\% in 2010 to $20 \%$ in 2017 [4]. Among current smokers, $4.3 \%$ are using electronic cigarettes, while among the general population only $1.7 \%$ of respondents report using electronic cigarettes regularly. Still, about 7.2 million people in Ukraine smoke every day [4].

It is worth keeping in mind that just 17 years ago smoking prevalence in the country has been on a dramatic rise, with an increase of male smokers from $54.8 \%$ in 2001 to $66.8 \%$ in 2005 , and of female smokers from $11.5 \% 2001$ to $20 \%$ in 2005 . In those years, the smoking prevalence was highest among men aged 30-59 and among women aged 15-29. Despite this alarming increase in 2001-2005 [3], the trend has been reversed, and smoking prevalence has fallen by $37 \%$ from 2010 to 2017 among Ukrainians aged 15-24 [4]. In the last years prevalence of daily smoking among men has continued to decrease, falling from $45.1 \%$ in 2010 to $35.9 \%$ in 2017 , while such a sharp decline has not been observed among women, who have experienced a slight decrease in daily smoking from $8.4 \%$ in 2010 to $7 \%$ in 2017 [4].

Another source that helps observe the trends smoking prevalence in Ukraine is data from the annual household survey published by State Statistics Committee of Ukraine (Fig. 1). The survey asked household members (aged 12+) about their cigarette smoking status. According to this survey, the smoking prevalence has changed 
from $23.6 \%$ in 2000 to $25.6 \%$ in 2008 and later started to fall from $23.5 \%$ in 2009 to $18.7 \%$ in 2017 [1, 9]. Despite the informative content of the annual household data it also has some limitations, such as the validity of self-reported smoking behavior, and audited census data that may lead to biased information for sampling.

Overall, multiple types of surveillance data confirm that prevalence of smoking is decreasing in Ukraine. This should be a powerful tool to advocate for implementation of novel WHO FCTC measures in Ukraine in order to maintain the current trend of smoking prevalence reduction.

\section{IMPACT ON LIFE EXPECTANCY AND PREMATURE MORTALITY}

Life expectancy in Ukraine dropped sharply at the end of the 1980s and started gradually rising again from the mid-1990s, as presented in Figure 2. However, Ukraine still has one of the lowest life expectancies in Europe [10]. As of 2016, life expectancy at birth in Ukraine stands at 71.5 years, 67 years for men and 77 years for women. The current gender gap in life expectancy in Ukraine is thus 10 years, as presented in Figure 3. This makes Ukraine the country with one of the largest gaps in life expectancy between men and women, similar to Belarus and Russia, and in contrast with Iceland and Israel, countries in which the gap amounts to just 3 years [11].

In Ukraine and Eastern Europe, trends of cigarette consumption are considered to be among the key contributors to the observed changes in life expectancy differences between men and women. The gender gap in life expectancy is primarily attributed to non-biological factors such as alcohol-related mortality, external causes of death (accidents, poisoning, homicides, self-harm),

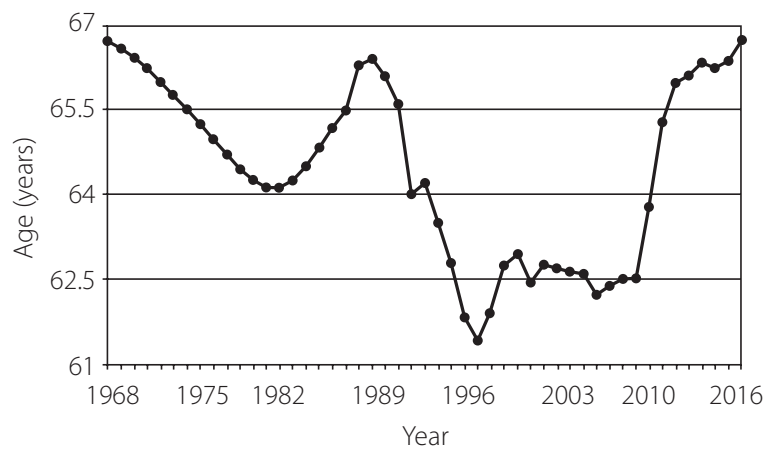

FIG. 2. Life expectancy at birth among Ukrainian men from 1968 till 2016. According to World Bank data

and tobacco-related mortality among the middle-aged population. These causes of death have been dramatically affecting men in Eastern Europe. Public health policies that would facilitate a drop in smoking prevalence should be implemented to help reduce the gender gap in life expectancy through driving a rise in life expectancy among middle-aged men in Ukraine [12].

Another consequence of tobacco consumption is premature mortality due to tobacco-related diseases. In Ukraine, this is observed predominantly among men [13]. According to Peto et al., 85,000 people died due to tobacco-related diseases in Ukraine in 2010, which constituted $12 \%$ of the overall mortality. Gender differences in mortality corresponded to 82,000 deaths among men (overall male mortality is $24 \%$ ) and 3,000 among women (overall female mortality is $0.9 \%$ ) [14]. It was estimated that by 2015 , the smoking-attributed mortality per year for all ages would decrease to 70,000 deaths among men, although tobacco-related deaths could slightly increase among women to 3,100 deaths annually. Peto et al. indi-

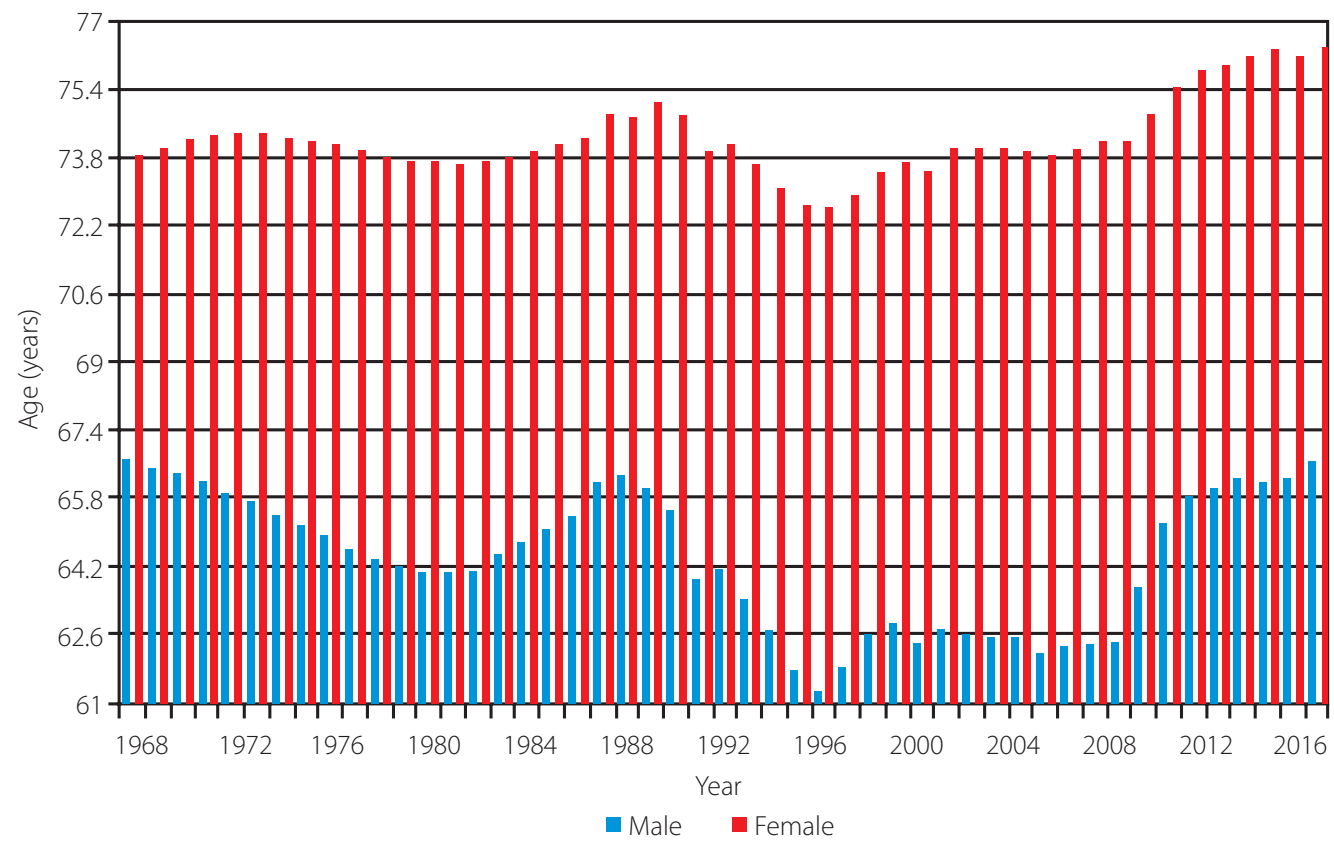

FIG. 3. Gender difference in life expectancy at birth, male and female, Ukraine, 1968-2016. According to World Bank data 
cate that the peak of smoking-attributed mortality stood at 138,000 deaths in 1995 [11].

Moreover, a recent study by the World Bank Group, focused on modeling the long-term health and cost impacts of reducing smoking prevalence through tobacco taxation in Ukraine, estimated that by 2035 , the $30 \%$ specific tax increase that was adopted in 2016 would result in the avoidance of 126,730 new cases of smoking-related morbidity, 29,172 premature deaths, and 267,098 potential years of life lost, relative to no change in tax [15].

To conclude, further implementation of the WHO FCTC policies may contribute to an increase of life expectancy, particularly among the male population. Any further reduction of smoking prevalence will be followed by a decrease in smoking-attributed mortality.

\section{CONCLUSIONS}

Evidence-based tobacco control policies have proven beneficial in fighting against smoking, and smokingattributed mortality and morbidity, in Ukraine. Nonetheless, Ukrainian lawmakers are still unwilling to implement novel WHO FCTC measures in the country. The tobacco industry and the front groups have an enormous influence on the policymaking process and continue to deny the effectiveness of tobacco control measures that have already proven to be the best practice. The progress of tobacco control and a further reduction of smoking prevalence in Ukraine depends on the political will. If evidence-based strategies for combatting the tobacco epidemic and novel endgame approaches are not implemented soon, the decline of smoking prevalence is likely to slow down during the next decade.

To achieve the goal of a tobacco-free Ukraine, and further reduce tobacco-attributable morbidity and mortality, the government needs to implement several policy initiatives; a point of sale display ban on tobacco products, a ban on tobacco advertising on the Internet, new pictorial health warnings covering $65 \%$ of tobacco packaging, and a ban on misleading information on cigarette packaging. Other necessary policies include regulation of the production, sale, and marketing of electronic cigarettes, prohibiting cigarettes with additives characterising the taste and smell of tobacco, expanding protection from second-hand smoke in public places, ensuring a high level of enforcement and compliance of tobacco control regulation, and establishing a system of disseminating information about health risks caused by tobacco products to the public [2].

\section{ACKNOWLEDGEMENTS}

Author would like to thank Oksana Totovytska and Felix Hoske for their comments on this article.

\section{DISCLOSURE}

The author reports no conflict of interest.

\section{References}

1. World Health Organization (WHO). Tobacco control in Ukraine: the national report. Copenhagen: WHO Regional Office for Europe; 2009: 11-15. Available from: http://www. euro.who.int/_data/assets/pdf_file/0009/82386/E93103.pdf (accessed: 11 May 2015).

2. World Health Organization Regional office for Europe. Press release. New laws to reduce access to tobacco products for youth in Ukraine. WHO Geneva 2017. Available from: http:// www.euro.who.int/en/countries/ukraine/news/news/2017/05/ new-laws-to-reduce-access-to-tobacco-products-for-youth-inukraine (accessed: 11 May 2015).

3. Andreeva TI, Krasovsky KS. Changes in smoking prevalence in Ukraine in 2001-5. Tobacco Control 2007; 16: 202-206.

4. World Health Organization (WHO). Global Adult Tobacco Survey - GATS. Report Ukraine 2017. Available from: https://www.kiis.com.ua/materials/pr/20180214_GATS/ Full\%20Report\%20GATS\%20Ukraine\%202017\%20ENG.pdf (accessed: 11 May 2015).

5. Transparency International Ukraine. Press release. Tobacco Manufacturers are Lobbying the Committee on Taxation through the "The Nasirov Group" - Research by TI Ukraine. Kyiv 2017. Available from: https://ti-ukraine.org/en/news/ tobacco-manufacturers-lobby-the-nasirov-group-interests-inthe-committee-on-taxation-research-by-ti-ukraine/ (accessed: 11 May 2015).

6. Transparency International Ukraine. Infographics. The 'lobbyists' of tobacco companies. Kyiv 2017. Available from: https://rpr.org.ua/wp-content/uploads/2018/03/Annual-Report-Transparency-Inernational-Ukraine-2017.pdf (accessed: 11 May 2015).

7. Tobacco control laws. Country legislation. Ukraine. Campaign for Tobacco-Free Kids. Washington D.C. 2017. Available from: https://www.tobaccocontrollaws.org/legislation/country/ ukraine/summary (accessed: 11 May 2015)

8. Law of Ukraine No. 2899-IV on Measures to Prevent and Reduce the Consumption of Tobacco Products and their Harmful Influence on the Population's Health, September 22, 2005 (as amended June 11, 2009 and Jan. 21, 2010). Available from: http://data.euro. who.int/tobacco/Repository/UA/Ukraine_\%20Law\%20On\%20 measures $\% 20$ to $\% 20$ prevent $\% 20$ and $\% 20$ reduce $\% 20$ the $\% 20$ consumption $\% 20$ of\%20tobacco\%20products_2005_consolidated\%20as\%20of\%202010_.pdf (accessed: 11 May 2015).

9. State Statistics Committee. Population's Self- perceived of Health Status and Availability of Selected Types of Medical Aid. Kyiv 2018. Available from: https:/ukrstat.org/en/operativ/operativ2007/ds/ nas_rik/nas_e/nas_rik_e.html (accessed: 11 May 2015).

10. Peabody JW, Luck J, DeMaria L, Menon R. Quality of care and health status in Ukraine. BMC Health Serv Res 2014; 14: 446.

11. World Bank Open Data. United Nations Population Division. World Population Prospects: 2017 Revision, or derived from male and female life expectancy at birth. Ukraine. Available from: https://data.worldbank.org/indicator/SP.DYN.LE00.IN?locations=UA (accessed: 11 May 2015). 
12. Luy M, Wegner-Siegmundt C. The impact of smoking on gender differences in life expectancy: more heterogeneous than often stated. Eur J Public Health 2015; 25: 706-710.

13. Gilmore A, Pomerleau J, McKee M, et al. Prevalence of smoking in 8 countries of the former Soviet Union: results from the living conditions, lifestyles and health study. Am J Public Health 2004; 94: 2177-2187.

14. Peto R, Lopez AD, Pan H, et al. Mortality from smoking in developed countries 1950-2000. Oxford University Clinical Trial Service Unit, Oxford 2015; 461.

15. Webber LEI, Andreeva T, Sotomayor N, et al. Modeling the long-term health and cost impacts of reducing smoking prevalence through tobacco taxation in Ukraine. World Bank Group Washington 2017. Available from: http://documents.worldbank org/curated/en/559401490166268124/Modeling-the-long-termhealth-and-cost-impacts-of-reducing-smoking-prevalencethrough-tobacco-taxation-in-Ukraine (accessed: 11 May 2015). 